\title{
Electrochemical Corrosion Behavior of TiN-coated 310S Stainless Steel in an Electric Water Heater in a Simulated Environment
}

\author{
Zhong Yin \\ Guangdong Midea Group Co., Ltd., Foshan 528311, Guangdong Province, China \\ E-mail: ZYYin_Midea@163.com
}

Received: 5 November 2021 / Accepted: 16 December 2021 / Published: 5 January 2022

\begin{abstract}
A uniform and dense TiN coating was successfully prepared on the $310 \mathrm{~S}$ stainless steel by magnetron sputtering. The morphologies and chemical composition of the TiN coating were analyzed by using scanning electron microscopy (SEM) and X-ray diffraction (XRD). The electrochemical corrosion behavior was investigated in a simulated electric water heater environment. The results reveal that the TiN coating exhibits good stability in synthetic tap water and $3.5 \% \mathrm{NaCl}$ solution at $80{ }^{\circ} \mathrm{C}$. The values of polarization resistance, corrosion potential and pitting potential of TiN-coated 310S stainless steel are much higher than those of the 310S substrate. It is suggested that TiN coatings can provide excellent corrosion resistance for 310S stainless steel in an aggressive environment containing chloride ions.
\end{abstract}

Keywords: 310 S stainless steel; TiN coating; Electrochemical corrosion; Tap water

\section{$\underline{\text { FULL TEXT }}$}

(C) 2022 The Authors. Published by ESG (www.electrochemsci.org). This article is an open access article distributed under the terms and conditions of the Creative Commons Attribution license (http://creativecommons.org/licenses/by/4.0/). 